\title{
Europe's research chiefs plan joint survey...
}

Munich. A coordinated study aimed at identifying gaps and weaknesses in Europe's basic research efforts is to be carried out by several European national research-funding bodies. The survey will be the first test of the ability of an informal group known as Eurohorcs (European heads of research councils) to organize a collaborative project.

The survey has been commissioned by the European Science and Technology Assembly (ESTA), the broad-based science advisory body of the European Commission. ESTA wants the survey to consider in particular whether any weaknesses it discovers are detrimental to the well-being and competitiveness of the research community. If so, it will suggest to the commission how such weaknesses could be corrected through the use of European Union funds.

The idea of a broad survey of this type was proposed more than a year ago by Sir Peter Swinnerton-Dyer, a former vicechancellor of the University of Cambridge and one of ESTA's 100 members. It was not taken up immediately because of the scale of the task, and a less detailed analysis is now being undertaken.

The survey is being organized by Richard Brook, chief executive of the UK Engineering and Physical Sciences Research Council. Brook has divided the task into nine scientific areas, responsibility for which has been divided among Eurohorc organizations. For example, the Italian research council (CNR) will analyse molecular and

\section{Taiwan finally clears nuclear power plant}

Hong Kong. Taiwan's parliament has finally given the go-ahead to a fourth and perhaps final nuclear power plant for the island, after a two-year argument over funding, which has frequently degenerated into public and parliamentary violence. Facing growing public opposition to nuclear power on grounds of safety and cost, the government has suggested that it may drop plans for two more stations, and that Taiwan's substantial energy needs may be met by other forms of power.

The Taiwanese opposition parties had voted against all funding for future nuclear projects, including this one, in May. But on 18 October a cabinet-led appeal vote was passed, as the opposition could not muster the two-thirds majority needed to block the appeal. The US\$6.7-billion station, $60 \mathrm{~km}$ north of Taipei at Kungliao, will be built by General Electric of the United States, and will use two Japanese boiling-water reactors, Japan's first nuclear reactor exports. Construction work is expected to begin this week and the plant should be on-stream by 2003.

Lis Tacey cellular biology, Germany's Max Planck Society will consider physics, and the UK Natural Environment Research Council will take on geology.

Representatives of the nine research agencies will meet in Brussels within the next few weeks to draw up a common set of criteria for assessing the research in their respective fields. They will then each set up an international panel to gather information from each country.

Brook has set a tight deadline for completion of the survey, which he says he will present to ESTA by the end of next March. The term of office of the current assembly expires in the middle of next year, when half of its members will be re-elected.

Brook and Jan Borgmann, chairman of
ESTA and formerly head of the Netherlands' National Research Council, both accept that the survey will inevitably be slightly superficial. But Borgmann sees it as a pilot, to be repeated later in more depth.

Brook says that the survey will also be a way of testing the muscle of the Eurohorcs group, which, because of its informal nature and lack of a permanent secretariat, has so far had a low-key presence on the research scene. "It will be a test to see if Eurohorcs can do something effectively and collaboratively," he says, adding that it should also help national governments to set their own research priorities by providing a better understanding of the broader European context in which their research takes place.

Alison Abbott

\section{... as citation 'landscape' takes shape}

Washington. The concept of a scientific 'landscape' is being given a literal interpretation by researchers at the Sandia National Laboratory in Albuquerque, New Mexico, who have developed a computer tool that shows up scientific trends as ripples, flows, peaks and gorges on a threedimensional map.

The 'landscapes' are based on data on the cross-citation of scientific literature compiled by the Institute for Scientific Watching the peaks: but where is Silicon Valley? Information (ISI), the Philadelphia-based organization that monitors citations of scientific literature worldwide.

The goal is to provide a way of visualizing the ebb and flow of activity in different science disciplines. Exploration of the landscapes will also identify where cooperation is strong between closely related fields of activity, and where it is weak.

Chuck Meyers is manager of laboratorydirected research at Sandia, much of whose work involves research on nuclear weapons. He says the landscapes could provide new insights for policy-makers, corporations and even intelligence agencies wanting a better understanding of unfolding trends in science.

"People are always asking "where is the leading edge?' in research", says Meyers, but usually all they have to go on is a mixture of anecdotes and indigestible statistics. "Decision-makers need to be able to look at clear indicators of what's happening and not happening."

Sandia has initially built a landscape for just one field, analytical chemistry, based on 30,000 articles published since 1986. It is now inputting the rest of ISI's physical sciences database - three million articles

and their references - into what it calls "a huge supercomputer data matrix" which can be explored using virtual reality.

ISI has been working for years with simple, two-dimensional maps that show how closely different scientific disciplines relate to each other. But mathematicians at Sandia used a mathematical approach based on eigenvectors to make the time taken to run their program proportional to the number of articles, rather than to the square of that number. They then used an advanced virtual-reality tool called Muse to present the information on a computer screen and allow users to explore the landscape at will.

A statement from Sandia says that the idea "originally was conceived to help US intelligence", which is said to have become more active in scientific and industrial espionage as it searches for a post-Cold War role. But ISI hotly denies this.

Meyers says that no intelligence money was received for the project, which was paid for with funds that Sandia is allowed to spend as it wishes on exploratory research. Nevertheless, he says he is now talking to US intelligence about applying the landscapes.

Colin Macilwain 